Journal of Contemporary Educational Research

Research Article

\title{
An Analysis on the Teaching Reform of Data Structure Course in China
}

Chenjie Wang ${ }^{1}$, Xianglian Meng ${ }^{2 *}, \mathrm{Xia} \mathrm{Meng}^{3}$, $\mathrm{Li} \mathrm{Sui}^{4}$

${ }^{1}$ Computer science and networks, School of Engineering and Computer Science, Computer University of Hertfordshire, UK

${ }^{2}$ Software Engineering, School of Computer Information \& Engineering, Changzhou Institute of Technology, China ${ }^{3}$ Education, Department of Hotel Management, WuXi Higher Vocational School of Tourism \& Commerce, China

${ }^{4}$ School of Computer Information \& Engineering, Changzhou Institute of Technology, China

Funding: This work was supported in part by grants from Qinglan Project of Jiangsu Province(2020); High-level demonstration construction project of Sino-foreign cooperation in running schools in Jiangsu Province, Jiangsu Higher Educational Technology Research Association-2019 Higher Education Informatization Research Project (2019JSETKT035); Ideological and Political Special Project of Philosophy and Social Science Research Projects in Colleges and Universities in 2019 (2019SJB422).

\begin{abstract}
For the course of "Data Structures", this paper introduces the importance and existing problems of the data structure course. Through the literature and the current teaching in major universities, the existing teaching methods and their disadvantages are analyzed. The authors put forward teaching reform suggestions and designed an online course platform.
\end{abstract}

Key words: Data structure; Teaching reform; Online course

Publication date: October, 2020

Publication online: 31 October, 2020

*Corresponding author: Xianglian Meng, Mengx1@ czust.edu.cn

\section{Introduction}

As a basic course for computer and related majors, "Data Structure" course has always been valued by major universities. The main content of this course includes the basic operations of linear lists, the basic operations of stacks, the traversal of binary trees, the traversal of graphs, the implementation of search and sorting algorithms, etc. Published by Tsinghua University Press and written by Yan Weimin, the book "Data Structure" has become a classroom teaching material used by major universities ${ }^{[1]}$. The main purpose of this course is to enable students to master the basic theories and basic methods of data structures and algorithms, including the concepts and interrelationships of logical structures, storage structures, and data operations, and to improve students' programming capabilities for various data structures and algorithms, and improve students' practical application of data structures and algorithms. However, because the data structure course is full of concepts, abstract definitions, and complex algorithms, this course is a great challenge for teachers and students. In this work, the unsatisfactories teaching of this course have been analyzed, such as students have negative psychology of "fear of difficulties", lack of programming practice after class and teachers cannot clearly impart abstract conceptual knowledge to students $^{[2]}$.

\section{Literature Review and Present Situation}

The concepts of Data Structure are diverse, abstract, and 
algorithms are complex. Therefore, this course is not only difficult points for students but also challenges for teachers. Many domestic and foreign articles have also proposed plans for data structure curriculum reform. For example, Zhai $\mathrm{H}$ that discussed Seminar teaching method as popular teaching or academic communication method in European and American universities ${ }^{[3]}$. In order to improve the efficiency of practical teaching and stimulate students' interest in learning. Li Juan gave many reform ideas, such as strengthening the prerequisite courses, using problem teaching methods, making full use of modern teaching methods, and establishing excellent course websites ${ }^{[4]}$. Although there were many curriculum reform programs, most teachers still rely on textbooks too much and didn't make full
Structure" online course will exceed 3 million in 2020. More than $90 \%$ of the students are satisfied with this course learning and teaching mode (see Figure 1). The main satisfaction points were the improvement of learning efficiency and the enhancement of interest in course learning. Especially for online courses that included dynamic demonstrations of multimedia data structure algorithms, most students said that it was easier to understand abstract data structures and complex algorithms under such teaching methods. Most students who used the Blue Bridge practice system, an online programming platform for algorithm practice applications, should get excellent results and win awards in the Blue Bridge Cup competition.

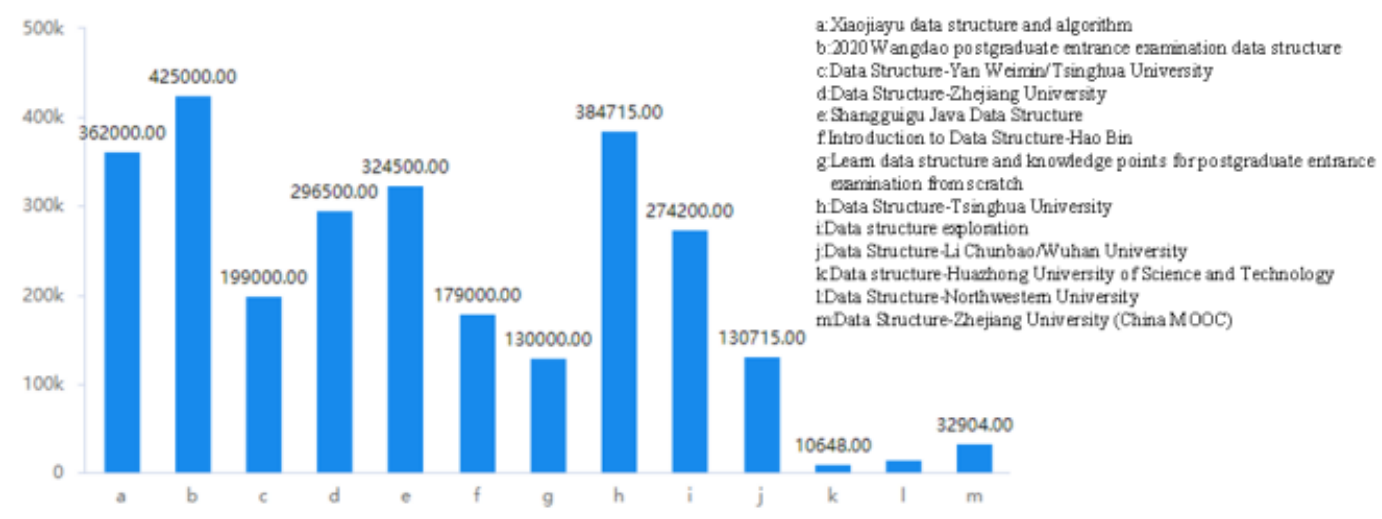

Figure 1. Statistics on the number of students in domestic data structure courses

use of teaching resources. In most universities, this course only have $42-48$ sessions. It was difficult to ensure that students should understand the teaching content in fast-paced teaching ${ }^{[5]}$. In addition, there were also shortcomings in homework and assessment after class. Most teachers only assign a few calculation questions or algorithm questions to require students to implement basic algorithms. It was difficult for students to get feedback in time and shouldn't integrate theory with practice to improve their learning and practical ability $^{[2]}$. In foreign countries, there was a teaching model that focuses on cultivating students' innovative ability, like visual teaching based on mind mapping ${ }^{[6]}$, focusing on practical teaching to cultivate application -oriented talents ${ }^{[7]}$, integrating project-based teaching, online learning, course experiment and design, process evaluation and comprehensive evaluation and other modes Teaching method $^{[8]}$.

\section{Online course statistics}

The number of broadcasts of the domestic "Data

\section{Suggestions and measures}

In view of the current problems in the teaching of this course, we conducted serious analysis and discussion, and proposed ideas for teaching reform. First, we should solve the shortcomings in teaching methods. In order to transfer abstract conceptual knowledge to students, teachers should make full use of modern teaching methods such as using multimedia teaching technology to dynamically demonstrate data structure algorithms. This will not only reduce the difficulty of teaching, facilitate students' understanding but also stimulate students' interest in learning.

Second, we should solve the problem of students' learning methods. The understanding ability of many students in the classroom is also quite different. The development of high-quality online course resources can facilitate students who cannot understand the content of the teacher in class to use the time after class to listen and understand repeatedly. Synchronize with other students. Students should combine the theories learned in class and apply them to example 
programming and practice more to achieve the learning goal of understanding data structure algorithms and being able to select appropriate algorithms when applied to examples. For example, when solving the map coloring, the shortest path problem, garbage classification, the Tower of Hanoi problem, etc., students can choose efficient data structures and algorithms for programming.

So we focused on combining theory with practice, developped an online programming platform for data structure and algorithm practice applications ${ }^{[4]}$, providing a large number of application examples and giving immediate feedback such as code length, CPU time and memory usage, helping students find insufficient code they have written and make improvements to improve students' ability to solve practical problems.

\section{Conclusion}

Through the teaching method reform of Data Structure course, the teaching efficiency of teachers will be improved. In the teaching method of multimedia presentation which is conducive to the faster understanding of students, and the teaching resources shared by the network platform will improve the teaching quality. The learning efficiency of students will be improved, mainly relying on better teaching, diversified data structure courses on the online classroom platform and a large number of practical exercises on the online programming platform. We will continue to improve our online platform based on students' usage

\section{References}

[1] Yan W, Wu W. Data Structure (in Chinese) [M]. Tsinghua University Press, 2002.

[2] Zhong F. 《Data Structure》 Research on the Design and Implementation of Network Courses (in Chinese) [J].Informa ionization of Education in China: Basic Education, 2013(4): 51-54.

[3] Zhai H. Discussion on the Reform of Practical Teaching of Data Structure and Algorithm Course [J]. Chongqing and the World (Academic Edition), 2013, 30(11): 93-95.

[4] Li J. Colleges 《Data Structure and Algorithm》 On the Reform of Course Teaching (in Chinese) [J]. Computer knowledge and technology (academic exchange), 2007(10): 240+256.

[5] Shi J, Li X, Lou J. Research on Algorithms and Data Structure Experimental Courses of Foreign High-level Universities [J]. Computer education, 2016(11): 163-166.

[6] Xin Liu. The Teaching Reform of Data Structure Centered on the Cultivation of Innovation Ability: Taking Local Undergraduate College as an Example[C]. AEIC Academic Exchange Information Centre (China),2018: 669-673.

[7] Ding L. The discussing on teaching reform of "Data structure" course in application- oriented universities[C]. Proceedings of 2015 2nd International Conference on Education, Management and Computing Technology (ICEMCT 2015). (Computer Science and Electronic Technology International Society),2015: 1128-1132.

[8] Xiao J, Liu X, Wang R. Application of Blended Learning in Data Structures and Algorithms Course Teaching[C]. (Computer Science and Electronic Technology International Society). (Computer Science and Electronic Technology International Society), 2013: 1071- 1075. 